\title{
Value of procalcitonin for diagnosing perioperative pneumonia, urinary infections and superficial surgical site infections in patients undergoing primary hip and knee arthroplasty
}

\author{
LIXUAN ZHANG ${ }^{1,2}$, DAOZHANG CAI ${ }^{1}$ and HANMING GUO ${ }^{2}$ \\ ${ }^{1}$ Department of Orthopedics, The Third Affiliated Hospital, Southern Medical University, Guangzhou, Guangdong 510630; \\ ${ }^{2}$ Department of Orthopaedic Surgery, Huizhou Municipal Central Hospital, Huizhou, Guangdong 516001, P.R. China
}

Received February 3, 2017; Accepted July 14, 2017

DOI: $10.3892 /$ etm.2018.6124

\begin{abstract}
Serum procalcitonin (PCT) levels may be helpful for the diagnosis of infections during the perioperative period of arthroplasty. However, there is much debate in the literature regarding the appropriate cut-off value for different types of surgery and local bacterial infection. The present study aimed to evaluate serum PCT levels in patients undergoing arthroplasty and to determine the cut-off value that may represent perioperative pneumonia, urinary infections and superficial surgical site infections. The present retrospective study included a total of 500 patients treated between July 2014 and August 2015. The case group contained 25 patients with perioperative infections (pneumonia, urinary and superficial surgical site infections), and the control group contained 25 patients without any post-surgical complications. Serum levels of PCT and white blood cells (WBC) were measured pre-operatively (D0) and at post-operative D4, D6 and D8, and the sensitivity, specificity and predictive value of these parameters were assessed. Regarding the comparison of the mean PCT levels between the case and the control group, a significant difference was seen at $\mathrm{D} 8(\mathrm{P}=0.007)$, while no significant differences were observed at D0 $(\mathrm{P}=0.010), \mathrm{D} 4(\mathrm{P}=0.069)$ and D6 ( $\mathrm{P}=0.093)$. No statistically significant differences in WBC levels between groups were observed for $(\mathrm{P}>0.01)$. In the control group, the PCT levels at D4 $(0.062 \pm 0.020 \mathrm{ng} / \mathrm{ml})$ were 2-fold of the mean baseline value, followed by a decrease until D6 $(0.051 \pm 0.019 \mathrm{ng} / \mathrm{ml})$ and a return close to the normal range by $\mathrm{D} 8(0.032 \pm 0.015 \mathrm{ng} / \mathrm{ml})$. The PCT levels in the case group had rapidly increased on D4 $(0.510 \pm 1.208 \mathrm{ng} / \mathrm{ml})$. In contrast to the control group, they continuously increased on
\end{abstract}

Correspondence to: Dr Daozhang Cai, Department of Orthopedics, The Third Affiliated Hospital, Southern Medical University, 183 Zhongshan Avenue West, Guangzhou, Guangdong 510630, P.R. China

E-mail: 616596892@qq.com

Key words: procalcitonin, white blood cell count, perioperative infection, arthroplasty
D6 $(0.527 \pm 1.360 \mathrm{ng} / \mathrm{ml})$ and D8 $(0.686 \pm 1.117 \mathrm{ng} / \mathrm{ml})$. From a clinical point of view, infection events were indicated in these patients during post-operative follow-up. For PCT, the area under the receiver operating characteristic curve (AUC) was 0.978 [95\% confidence interval (CI), 0.933-1.022], and for WBC, the AUC was 0.562 (95\% CI, 0.398-0.0.726). Based on the above data, the PCT value was a significant predictor of infection (AUC>0.9). For PCT, the cut-off point of $0.0995 \mathrm{ng} / \mathrm{ml}$ was associated with a sensitivity of $96 \%$ and a specificity of $100 \%$. However, WBC were not a significant predictor of infection $(0.5<\mathrm{AUC}<0.7)$, and the cut-off value of $7.05 \times 10^{9} / 1$ was associated with a sensitivity of $64 \%$ and a specificity of $44 \%$. In conclusion PCT was found to be a promising marker for diagnosing bacterial infections post- arthroplasty due to its high specificity. Based on the sensitivity and the specificity, detecting PCT may be more valuable than using WBC in the diagnosis of sepsis-associated pathological changes in the perioperative period.

\section{Introduction}

Postoperative infections associated with implants are one of the most challenging complications after arthroplasty; they may cause increased cost, hospitalization stays as well as mortality and morbidity rates (1). Any type of infection, including pneumonia, urinary tract infections (UTI) and superficial surgical site infections (SSI) should be cured during the perioperative period of arthroplasty and may lead to periprosthetic joint infection. Thus, it is crucial to detect any infections during the perioperative period of arthroplasty in order to rapidly initiate adequate antimicrobial therapy (2-4). In the diagnostic process for detecting a perioperative infection, one of the most important steps is the analysis of laboratory biomarkers of infection. Biomarkers, such as white blood cell count (WBC), erythrocyte sedimentation rate (ESR) and C-reactive protein (CRP) may be used to aid in the diagnosis, therapeutic monitoring and risk stratification. However, these blood parameters lack sensitivity and specificity in discriminating inflammation due to a bacterial infection from that of a surgical injury response (5-10). In addition, due to the low positivity rate of pus culture, this gold standard has low sensitivity. Thus, the search for realistic laboratory markers is essential. Previous studies have 
reported that due to its high specificity, procalcitonin (PCT) is comparatively more useful for diagnosing bacterial infections, including sepsis, upper respiratory tract infections, pneumonia, pancreatitis, pyelonephritis and burns (11-13). PCT, the 116-amino acid prohormone of calcitonin, is mainly produced as a precursor hormone of calcitonin by the neuroendocrine cells of the thyroid and lung; alternative pathological pathways in patients with inflammation and sepsis have been described. Bacterial endotoxins have been reported to release PCT directly into the circulation $(14,15)$. PCT typically increases 2 to $4 \mathrm{~h}$ following an appropriate exposure such as sepsis (16-20); it reaches its peak after $6 \mathrm{~h}$ and has a half-life of 25-30 $\mathrm{h}(21,22)$. A rapid decline occurs following treatment or removal of the underlying trigger. Compared with CRP, which only reaches a maximum after $36 \mathrm{~h}(23,24)$, PCT may be detected sooner. The features of PCT suggests that detecting PCT levels may be better than WBC and CRP for differentiating between sepsis, aseptic inflammation and traumatic injury in certain clinical settings, particularly following orthopaedic surgery. However, only a small number of studies (25) have investigated the value of diagnosing perioperative infection by detecting PCT levels during the period of primary hip and knee arthroplasty and comparing them with other biomarkers, such as WBC. Thus, it appeared worthwhile to perform a study to determine the specificity and the sensitivity of the characteristics of PCT for diagnosing infections during the perioperative period of arthroplasty. As the serum levels of PCT and WBC are measured in all patients undergoing arthroplasty at our department, it was possible to perform a retrospective study. The present study aimed to evaluate the serum PCT levels in patients with perioperative infection following arthroplasty and to determine the cut-off value that it may represent. The present study hypothesized that the elevation of PCT levels in patients undergoing primary arthroplasty may help to detect perioperative infections.

\section{Patients and methods}

Study design and inclusion criteria. The cohort analysis for this retrospective study was approved by the local Ethics Committee of Huizhou Municipal Central Hospital (Huizhou, China). Data were obtained from the hospital's electronic medical record system. Two patient cohorts who were treated between July 2014 and August 2015 at the Department of Orthopaedic Surgery (Huizhou Municipal Central Hospital, Huizhou, China) were enrolled. A consecutive series of patients undergoing primary hip and knee arthroplasty was retrospectively reviewed and all patients who developed postoperative infections, including pneumonia and UTI occurring within two weeks and superficial SSI occurring within 30 days (case group) were included. A tourniquet was used during the knee surgery, and the duration was 60-90 min. Antiseptic agent (iodine) was used on all patients and sterile covering for preoperative skin preparation was performed; furthermore, the skin incisions were mended using the same method of suture. None of the patients of the present study received any postoperative blood transfusion.

The inclusion criteria for the case group diagnosis with pneumonia, UTI or superficial SSI. A diagnosis of pneumonia required a new pulmonary infiltrate at the time of hospitalization, and at least one of the following: New or increased cough, leukocytosis, leukopenia or left shift pattern on WBC count, and a body temperature of $>37.8^{\circ} \mathrm{C}$ or $<35.6^{\circ} \mathrm{C}$. A diagnosis of UTI required at least one of the following symptoms, such as fever $\left(>38^{\circ} \mathrm{C}\right)$, dysuria, pollakiuria, suprapubic tenderness and having $\geq 10^{5}$ colony-forming units $/ \mathrm{ml}$ of one or two types of bacteria; for culture-negative patients, at least two of the above-mentioned symptoms and one of the seven criteria defined by the Centers for Disease Control and Prevention, such as nitrite test positivity and pyuria, were required for inclusion in the study (26). Asymptomatic patients were excluded. The diagnosis of a superficial SSI included an infection occurring within 30 days after the operation on a surgical site, except for deep incisional SSI and periprosthetic joint infections (PJI) $(27,28)$. As presented in Table I, the classification of SSI categorizes the infection into three groups, namely superficial incisional, deep incisional and organ-space SSI (28).

A retrospective chart review was performed for each surgical site to identify patients who met the inclusion criteria for the case group. The control group was selected based on a randomization table to gather a matched number of patients from those treated during the same time span as the control group. Patients in the control group underwent primary hip and knee arthroplasty but did not develop any postoperative infection complications during the inpatient stay, in the first month after operation, and at the final 12-24-month follow-up exam. Patients of the case and the control group were excluded from the study if they met one of the following exclusion criteria: Possible precondition for elevated inflammatory markers, including chronic inflammatory diseases, obesity (body mass index, $>30 \mathrm{~kg} / \mathrm{m}^{2}$ ), viral infections, malignancies, heavy smoking, inflammation other than an orthopaedic infection (e.g., autoimmunity, intercurrent febrile infection) for the purpose of avoiding interference with other inflammatory processes, and patients with hepatic failure, or deficiencies of the kidneys or the immune system.

Based on the inclusion criteria, a total of 500 patients were reviewed to obtain 25 patients with perioperative infections in the case group, and 25 patients without any associated complications were enrolled in the control group. The mean levels of WBC and PCT were compared between these groups, and the sensitivity, specificity and predictive values of WBC and PCT were assessed.

Laboratory analyses. Blood samples for analysis had been collected at the following time-points: Preoperatively (D0) and on day 4 (D4), D6 and D8 post operation. Blood was taken from the cubital vein. Serum levels of PCT were measured using a KRYPTOR electrochemiluminescence immunoassay and a Cobas 8000 modular analyser (Roche Diagnostics $\mathrm{GmbH}$, Mannheim, Germany) and WBC were measured using an XE-5000 automated hematology system (Sysmex Corp., Kobe, Japan) at the Institute of Clinical Chemistry of Huizhou Municipal Central Hospital (Huizhou, China).

Statistical analysis. Descriptive data analyses were performed using SPSS version 19.0 for Windows (IBM Corp., Armonk, NY, USA). Prior to assessing the association or difference, a one-Sample Kolmogorov-Smirnov test was used to assess descriptive values for normality. For comparing the difference 
Table I. Classification of SSI.

Type of SSI Definition

Superficial incisional SSI

Deep incisional SSI

Organ or space SSI
Infection involves only skin or subcutaneous tissue and at least one of the following:

-Purulent drainage from the superficial incision, with or without laboratory result -Isolated microorganism from a culture of fluid or tissue

-Pain, swelling, heat or redness at the surgical site

-Diagnosis of superficial incisional SSI established by surgeon or attending physician Infection involves deep soft tissues such as fascia or muscle layer and at least one of the following:

-Purulent drainage from the deep incision but not from organ or organ space component -A deep incision spontaneously dehisces or is deliberately opened by a surgeon when the patient has at least one of the following signs: Fever $\left(>38^{\circ} \mathrm{C}\right)$, localized pain or tenderness

-An abscess or other evidence of deep infection that is found on direct histopathological or radiological examination

-Diagnosis of deep incisional SSI made by a surgeon or attending physician

Infection involves organs or spaces, other than the incision site and at least one

of the following:

-Purulent drainage from the organ or space

-Isolated microorganism from a culture of fluid or tissue

-An abscess or other evidence of deep infection that is found on direct examination or on histopathological or radiological examination

-Diagnosis of organ/space SSI by a surgeon or attending physician

SSI, surgical site infection.

between two independent samples, the Mann-Whitney U-test was used if the descriptive statistics had an abnormal distribution; otherwise, the Student's t-test was used. For comparing the constituent ratio difference between two independent samples, Pearson's Chi-square test was used. A box plot was used to display the distribution range of PCT levels. Receiver operator characteristic (ROC) curves were generated to determine the best cut-off values and to calculate individual specificity and sensitivity for PCT and WBC. P $<0.01$ was considered to indicate a statistically significant difference.

\section{Results}

Patient characteristics. A total of 50 patients were included in the present retrospective cohort study. In the case group $(n=25)$, 4 patients had pneumonia, 7 had UTI and 14 had superficial SSI. Indwelling catheters occurred in 6 patients of the case group and 2 patients of the control group. Among the 7 patients with UTI, 4 had indwelling catheters. Of the 25 patients in the case group, 20 underwent total hip arthroplasty (THA) and the other 5 underwent total knee arthroplasty (TKA). Of the 25 patients in the control group, 14 underwent THA and the other 11 underwent TKA. Except at D8 in the control group $(\mathrm{P}<0.01)$, no significant difference was identified in the PCT levels between patients who underwent THA and those who underwent TKA, including D0, D4, D6 and D8 ( $>>0.01)$. However, 5 patients required additional surgical debridement, and all of the 14 patients with SSI recovered following treatments including prolonged hospital stay and antibiotics.
The patient demographics are provided in Table II. There were no significant differences in age $(\mathrm{P}=0.056)$, patient gender $(\mathrm{P}=0.508)$ or joint distribution $(\mathrm{P}=0.069)$ between the groups.

All data of the present study followed a normal distribution. Comparison of the means of the PCT levels between the case and the control group indicated a significant difference at D8 $(\mathrm{P}=0.007)$, while no significant difference was observed at D0 ( $\mathrm{P}=0.01), \mathrm{D} 4(\mathrm{P}=0.069)$ and $\mathrm{D} 6(\mathrm{P}=0.093)$. In addition, no statistical significance was observed regarding the differences in WBC levels between the two groups ( $\mathrm{P}>0.01$; Table III).

In the control group, the mean serum levels of PCT at D0 $(0.031 \pm 0.011 \mathrm{ng} / \mathrm{ml})$ were in the normal range $(0-0.05 \mathrm{ng} / \mathrm{ml})$ and had increased by two-fold by D4 $(0.062 \pm 0.020 \mathrm{ng} / \mathrm{ml})$. However, it had rapidly decreased by D6 $(0.051 \pm 0.019 \mathrm{ng} / \mathrm{ml})$ and returned to the normal range on D8 $(0.032 \pm 0.015 \mathrm{ng} / \mathrm{ml}$; Fig. 1). Although the preoperative mean serum levels of PCT in the case group $(0.121 \pm 0.166 \mathrm{ng} / \mathrm{ml})$ were higher than those in the control group $(0.031 \pm 0.011 \mathrm{ng} / \mathrm{ml})$, no statistical significance was observed. Similarly to those in the control group, the PCT levels in the case group had rapidly increased on D4 $(0.510 \pm 1.208 \mathrm{ng} / \mathrm{ml})$; however, they continuously increased on D6 (0.527 $\pm 1.360 \mathrm{ng} / \mathrm{ml})$ and D8 (0.686 $\pm 1.117 \mathrm{ng} / \mathrm{ml}$; Fig. 2). From a clinical point of view, infection events were indicated in these patients during the postoperative period.

To measure the best cut-off values and calculate the individual specificity and sensitivity of PCT and WBC, ROC curves were generated (Fig. 3). A summary of the results is provided in Table IV. To compare the capability of the two biomarkers to distinguish between patients without infection 
Table II. Patient demographics.

\begin{tabular}{lcccc}
\hline Group & Patients (n) & Mean age (years) & Sex (female/male) & Hip/knee arthroplasty \\
\hline Case & 25 & $69.12 \pm 9.94$ & $18 / 7$ & $20 / 5$ \\
Control & 25 & $63.28 \pm 11.13$ & $20 / 5$ & $14 / 11$ \\
t-test & & 1.956 & 0.439 & 3.309 \\
P-value & & 0.056 & 0.508 & 0.069 \\
\hline
\end{tabular}

Values are expressed as $\mathrm{n}$ or as the mean \pm standard deviation.

Table III. Descriptive statistics of parameters at various perioperative time-points.

\begin{tabular}{|c|c|c|c|c|c|c|c|c|}
\hline \multirow[b]{2}{*}{ Group } & \multicolumn{4}{|c|}{ PCT (ng/ml) } & \multicolumn{4}{|c|}{$\mathrm{WBC}\left(\mathrm{x} 10^{9} / 1\right)$} \\
\hline & D0 & D4 & D6 & D8 & D0 & D4 & D6 & D8 \\
\hline Case & $0.121 \pm 0.166$ & $0.510 \pm 1.208$ & $0.527 \pm 1.360$ & $0.686 \pm 1.117$ & $7.556 \pm 3.037$ & $7.932 \pm 2.266$ & $8.336 \pm 2.777$ & $8.148 \pm 2.013$ \\
\hline Control & $0.031 \pm 0.011$ & $0.062 \pm 0.020$ & $0.051 \pm 0.019$ & $0.032 \pm 0.015$ & $7.036 \pm 2.537$ & $7.636 \pm 1.681$ & $8.892 \pm 2.013$ & $8.548 \pm 2.252$ \\
\hline t-test & 2.697 & 1.859 & 1.750 & 2.925 & 0.657 & 0.525 & -0.811 & -0.662 \\
\hline P-value & 0.01 & 0.069 & 0.093 & 0.007 & 0.514 & 0.602 & 0.422 & 0.511 \\
\hline
\end{tabular}

PCT, procalcitonin; WBC, white blood cells; D0, pre-surgery/baseline; D4, day 4 post-surgery.

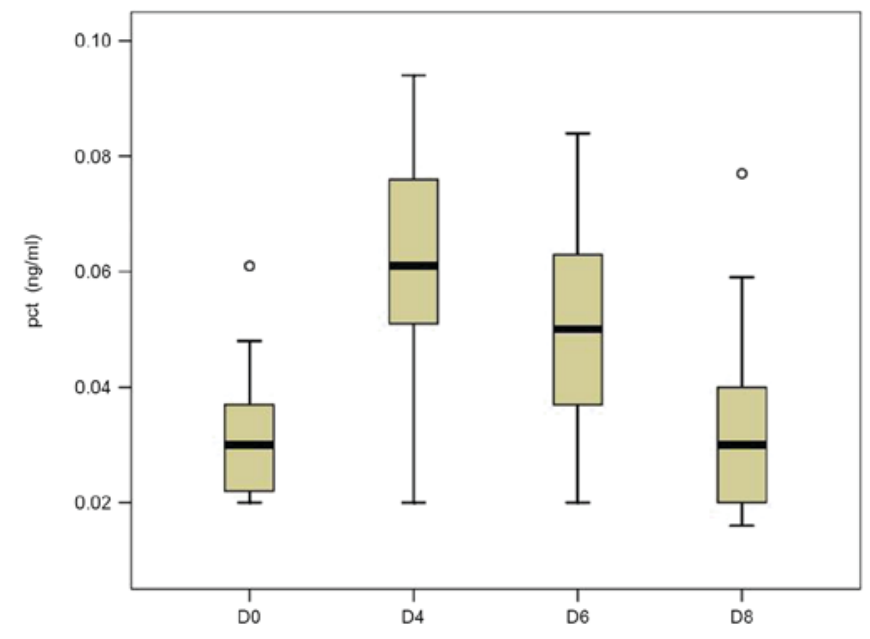

Figure 1. PCT serum levels at various perioperative time-points in the control group. Boxes indicate the median and interquartile range; whiskers indicate the highest and lowest values; circles indicate outliers. PCT, procalcitonin; D0, pre-surgery/baseline; D4, day 4 post-surgery.

from those with infection, the area under the curve (AUC) was calculated. For PCT, the AUC was 0.978 [95\% confidence interval (CI), 0.933-1.022]; for WBC, the AUC was $0.562(95 \%$ CI, 0.398-0.0.726). Based on the above data, the PCT value was a significant predictor of infection (AUC $>0.9$ ). For PCT, the cut-off point of $0.0995 \mathrm{ng} / \mathrm{ml}$ was associated with a sensitivity of $96 \%$ and a specificity of $100 \%$ (Fig. 3). At a cut-off of $0.526 \mathrm{ng} / \mathrm{ml}$, PCT was found to be $36 \%$ sensitive and $100 \%$ specific in diagnosing infections. However, WBC was not a significant predictor of infection $(0.5<\mathrm{AUC}<0.7)$. A WBC value of $7.05 \times 10^{9} / 1$ was associated with a sensitivity of $64 \%$ and a specificity of $44 \%$. For combining different parameters,

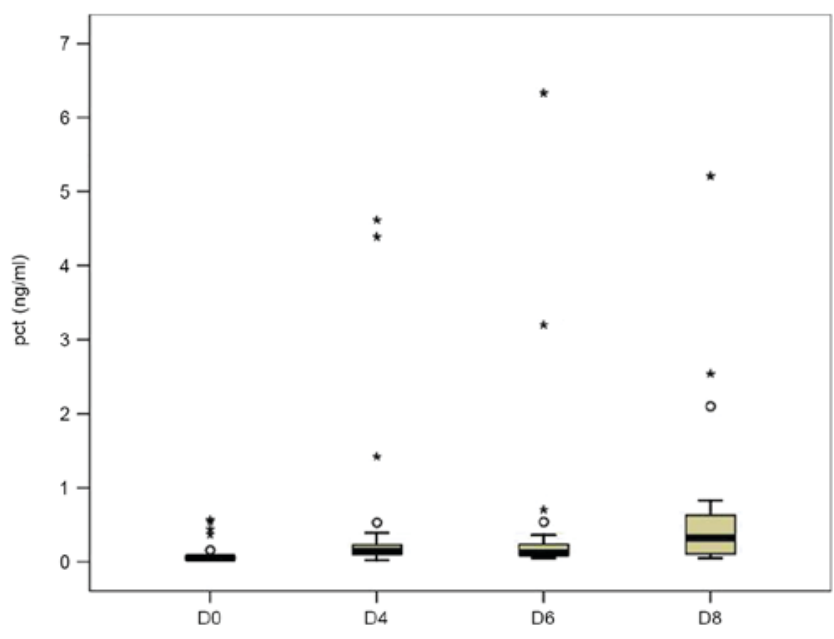

Figure 2. PCT serum levels at various perioperative time-points in the case group. Boxes indicate the median and interquartile range; whiskers indicate the highest and lowest values; circles indicate outliers; asterisks indicate extreme outliers. PCT, procalcitonin; D0, pre-surgery/baseline; D4, day 4 post-surgery.

the point with the minimal distance on the ROC curve was considered to be the optimal threshold. Obviously, PCT had a higher sensitivity and specificity compared with WBC.

\section{Discussion}

Any infections, including pneumonia, UTI and superficial SSI, are dangerous during the perioperative period of arthroplasty, as they may lead to the occurrence of PJI, a serious postoperative complication following arthroplasty (29-31). To prevent unnecessary PJI following perioperative infections, an early and correct diagnosis is important. The present study 
Table IV. Results of the receiver operating characteristic curve analysis.

\begin{tabular}{lccrr}
\hline Parameter & AUC $(95 \% \mathrm{CI})$ & Cut-off $(\mathrm{ng} / \mathrm{ml}$ or $1 / \mathrm{l})$ & Sensitivity $(\%)$ & Specificity $(\%)$ \\
\hline PCT & $0.978(0.933-1.022)$ & 0.0565 & 100 & 40 \\
& & 0.059 & 96 & 48 \\
& & 0.0995 & 36 & 100 \\
WBC & $0.562(0.398-0.726)$ & 0.526 & 100 & 0 \\
& & $3.2 \times 10^{9}$ & 64 & 46 \\
\end{tabular}

PCT, procalcitonin; WBC, white blood cells; AUC, area under the receiver operating characteristic curve; CI, confidence interval.

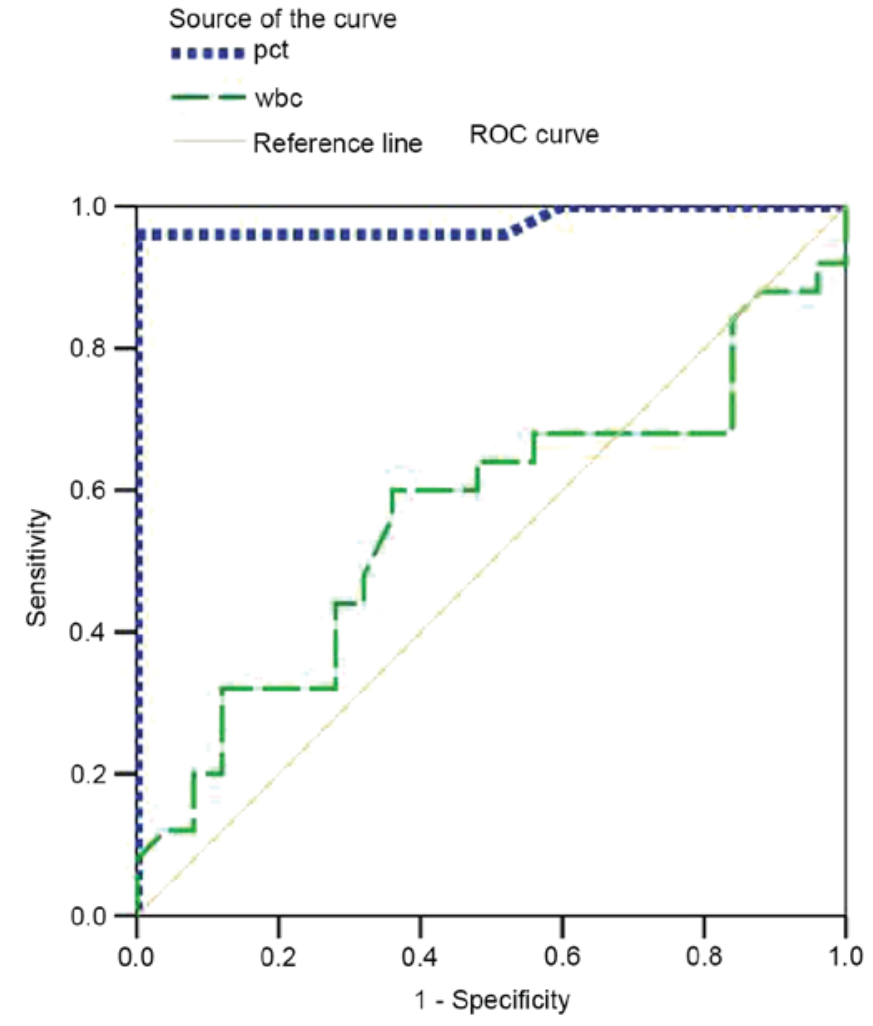

Figure 3. ROC curves for PCT and WBC. PCT, procalcitonin; WBC, white blood cells; ROC, receiver operating characteristic.

retrospectively analysed the plasma concentration of PCT and the WBC with regard to their sensitivity and specificity for detecting perioperative infections.

PCT, the 116-amino-acid prohormone of calcitonin, is mainly produced by the parafollicular cells of the thyroid in healthy individuals, while alternative pathological pathways have been described in patients with inflammation and sepsis. PCT is widely used as a diagnostic marker of sepsis and systemic inflammatory response syndrome (32), and has been demonstrated to be a more accurate marker for the detection of early postoperative infection after cardiac, intestinal and major neural surgeries compared with standard laboratory parameters, such as CRP and WBC (33-36). In these cases, inflammatory cytokines, such as tumor necrosis factor- $\alpha$, interleukin- $1 \beta$ and fragments of cell walls or membranes of microbes, such as lipopolysaccharides or peptidoglycans, may induce PCT production. In the control group, the mean serum concentrations of PCT peaked at D4 and had decreased on D6 post surgery. Surgical trauma may have been the cause of the transient elevation of PCT. Due to the consistent and rapid increase in PCT levels post surgery in the case group, the PCT trend may be used as a marker for possible infection in the early postoperative period. In the control group, none of the patients had any perioperative infection. The preoperative results in the control group convincingly demonstrated that aseptic pathological changes in hip and knee did not cause any significant increases in PCT. These findings indicated that a sudden elevation at D6 is suggestive of a bacterial infection; this was indicated in the case group, in which a sudden and continuous elevation of PCT levels was identified. In addition, the post-operative levels of PCT in the case group were much higher than those commonly seen in the control group. In the case group, the most common type of infection was superficial SSI, which was seen in 14 patients (56\%), while 7 patients $(28 \%)$ had a UTI and 4 patients $(16 \%)$ had pneumonia. Among the 7 patients with a UTI, 4 patients had indwelling catheters; therefore, an indwelling catheter was likely to be one of the factors causing UTI. Previous studies reported that $70-80 \%$ of complicated UTIs are attributable to indwelling catheters in the US (37), accounting for $\sim 1$ million cases per year (38). All of the infections were caused by various bacteria. Bacterial endotoxins have been reported to release PCT directly into the circulation $(14,15)$. PCT increases at 2-4 $\mathrm{h}$ following an insult such as sepsis (16-20), reaches its peak after $6 \mathrm{~h}$ and has a half-life of 25-30 h $(21,22)$. A rapid decline occurs following treatment or removal of the underlying trigger. Based on the results of the present study, the serum PCT levels continue to increase from D6 to D8 post surgery if an infection is present; therefore, any significant elevations of PCT at D6 may suggest the occurrence of infection or a different type of inflammation. Based on these results, attention should be paid on the SSI, the most common type of perioperative infection, and approaches to reduce the risk of SSI, including antimicrobial prophylaxis, preoperative optimization of anaemia and diabetes, preoperative chlorhexidine washes and adjustment of operation duration should be pursued. In addition, routine use of an indwelling catheter is not recommended due to it being one of the factors causing UTI. 
Although numerous studies have reported that the highest serum PCT values occur in patients with sepsis (32), they are also increased in inflammatory conditions, such as trauma following extensive surgery $(25,39,40)$. In addition, unspecific or trauma-associated induction of PCT has been reported during the perioperative period. Thus, it is important to determine cut-off values suitable for different types of surgery and local bacterial infections. In the present study, the kinetics of PCT were analysed in patients during the perioperative period of arthroplasty, including infection and aseptic cases. Previous studies suggested that PCT values of $>2 \mathrm{ng} / \mathrm{ml}$ are strongly indicative of sepsis or severe bacterial infection, while these condition are unlikely if PCT levels are $<0.5 \mathrm{ng} / \mathrm{ml}(41,42)$. Hügle et al $(43)$ demonstrated that PCT has high sensitivity but low specificity at a cut-off value of $0.25 \mathrm{ng} / \mathrm{ml}$. However, the present study identified that the cut-off point of $0.0995 \mathrm{ng} / \mathrm{ml}$ was associated with the highest sensitivity (96\%) and specificity (100\%). In addition, other studies reported that PCT is a marker with poor sensitivity but high specificity at a cut-off of $0.5 \mathrm{ng} / \mathrm{ml}(22,44,45)$. Bottner et al (46) reported a high specificity (98\%) but low sensitivity (33\%) in the detection of deep chronic periprosthetic infection for PCT levels with a cut-off at $0.3 \mathrm{ng} / \mathrm{ml}$. Similarly, in the present study, at a cut-off of $0.526 \mathrm{ng} / \mathrm{ml}$, PCT had $36 \%$ sensitivity and $100 \%$ specificity for diagnosing infections. For any novel diagnostic marker, balancing sensitivity and specificity is essential. In the present study, $0.0995 \mathrm{ng} / \mathrm{ml}$ was taken as the cut-off for diagnosing perioperative infection.

Of note, the present study had several limitations. Data were collected retrospectively from a single centre, and the sample size was low for a study investigating perioperative infections in patients undergoing primary hip and knee arthroplasty.

In summary, the present study suggested that PCT is a promising marker for diagnosing bacterial infections due to its high specificity. Based on the sensitivity and the specificity of PCT, detecting PCT may be more valuable than using WBC in the diagnosis of septic pathological changes in the perioperative period. Large retrospective studies analysing the serum PCT levels in patients with infections following primary hip and knee arthroplasty may provide further insight into the diagnostic value of PCT in the future.

\section{References}

1. Dale H, Hallan G, Hallan G, Espehaug B, Havelin LI and Engesaeter LB: Increasing risk of revision due to deep infection after hip arthroplasty. Acta Orthop 80: 639-645, 2009.

2. Costerton JW, Post JC, Ehrlich GD, Hu FZ, Kreft R, Nistico L, Kathju S, Stoodley P, Hall-Stoodley L, Maale G, et al: New methods for the detection of orthopedic and other biofilm infection. FEMS Immunol Med Microbiol 61: 133-140, 2011.

3. Savarino L, Baldini N, Tarabusi C, Pellacani A and Giunti A: Diagnosis of infection after total hip replacement. J Biomed Mater Res B Appl Biomater 70: 139-145, 2004.

4. Van Kleunen JP, Knox D, Garino JP and Lee GC: Irrigation and dèbridement and prosthesis retention for treating acute periprosthetic infections. Clin Orthop Relat Res 468: 2024-2028, 2010.

5. van Leeuwen MA and van Rijswijk MH: Acute phase proteins in the monitoring of inflammatory disorders. Baillieres Clin Rheumato 8: 531-552, 1994.

6. Rafiq M, Worthington T, Tebbs SE, Treacy RB, Dias R,Lambert PA and Elliott TS: Serological detection of Gram-positive bacterial infection around prostheses. J Bone Joint Surg Br 82: 1156-1161, 2000.

7. Itasaka T, Kawai A, Sato T, Mitani S and Inoue H: Diagnosis of infection after total hip arthroplasty. J Orthop Sci 6: 320-326, 2001.
8. Di Cesare PE, Chang E, Preston CF and Liu CJ: Serum interleukin-6 as a marker of periprosthetic infection following total hip and knee arthroplasty. J Bone Joint Surg Am 87: 1921-1927, 2005.

9. Mitaka C: Clinical laboratory differentiation of infectious versus non-infectious systemic inflammatory response syndrome. Clin Chim Acta 351: 17-29, 2005.

10. Falcoz PE, Laluc F, Toubin MM, Puyraveau M, Clement F, Mercier M, Chocron S and Etievent JP: Usefulness of procalcitonin in the early detection of infection after thoracic surgery. Eur J Cardiothorac Surg 27: 1074-1078, 2005.

11. Delèvaux I, André M, Colombier M, Albuisson E, Meylheuc F, Bègue RJ, Piette JC and Aumaître O: Can procalcitonin measurement help in differentiating between bacterial infection and other kinds of inflammatory processes? Ann Rheum Dis 62: 337-340, 2003.

12. Eberhard K, Haubitz M, Brunkhorst M, Kliem V and Koch M: Usefulness of procalcitonin for differentiation between activity of systemic autoimmune disease and invasive bacterial infection. Arthritis Rheum 40: 1250-1256, 1997.

13. Becker KL, Snider R and Nylen ES: Procalcitonin assay in systemic inflammation, infection and sepsis: Clinical utility and limitations. Crit Care Med 36: 941-952, 2008.

14. Dandona P, Nix D, Wilson MF, Aljada A, Love J, Assicot M and Bohuon C: Procalcitonin increase after endotoxin injection in normal subjects. J Clin Endocrinol Metab 79: 1605-1608, 1994.

15. Reinhart K, Karzai W and Meisner M: Procalcitonin as a marker of the systemic inflammatory response to infection. Intensive Care Med 26: 1193-1200, 2000.

16. Carrol ED, Thomson AP and Hart CA: Procalcitonin as a marker of sepsis. Int J Antimicrob Agents 20: 1-9, 2002.

17. Hunziker S, Hügle T, Schuchardt K, Groeschl I, Schuetz P, Mueller B, Dick W, Eriksson U and Trampuz A: The value of serum procalcitonin level for differentiation of infectious from noninfectious causes of fever after orthopaedic surgery. J Bone Joint Surg Am 92: 138-148, 2010.

18. Nascimento-Carvalho CM, Cardoso MR, Barral A, AraujoNeto CA, Guerin S, Saukkoriipi A, Paldanius M, Vainionpaa R, Lebon P, Leinonen M, et al: Procalcitonin is useful in identifying bacteraemia among children with pneumonia. Scand J Infect Dis 42: 644-649, 2010.

19. Pramod J and Singh A: Sepsis biomarkers. Am J Med 121: e11, 2008.

20. Ruiz-Alvarez MJ, García-Valdecasas S, De Pablo R, Sanchez García M, Coca C, Groeneveld TW, Roos A, Daha MR and Arribas I: Diagnostic efficacy and prognostic value of serum procalcitonin concentration in patients with suspected sepsis. J Intensive Care Med 24: 63-71, 2009.

21. Gendrel D and Bohuon C: Procalcitonin, a marker of bacterial infection. Infection 25: 133-134, 1997.

22. Martinot M, Sordet C, Soubrier M, Puéchal X, Saraux A, Lioté F, Guggenbuhl P, Legre V, Jaulhac B, Maillefert JF, et al: Diagnostic value of serum and synovial procalcitonin in acute arthritis: A prospective study of 42 patients. Clin Exp Rheumato 23: 303-310, 2005.

23. Simon L, Gauvin F, Amre DK, Saint-Louis P and Lacroix J: Serum procalcitonin and C-reactive protein levels as markers of bacterial infection: A systematic review and meta-analysis. Clin Infect Dis 39: 206-217, 2004.

24. Foglar C and Lindsey RW: C-reactive protein in orthopedics. Orthopedics 21: 687-691, 1998.

25. Meisner M, Tschaikowsky K, Hutzler A, Schick C and Schüttler J: Postoperative plasma concentrations of procalcitonin after different types of surgery. Intensive Care Medicine 24: 680-684, 1998.

26. Garner JS, Jarvis WR, Emori TG, Horan TC and Hughes JM: CDC definitions for nosocomial infections, 1988. Am J Infect Control 16: 128-140, 1988.

27. CDC: Surgical site infections: Resources for patients and healthcare providers. http://www.cdc.gov/ncidod/dhqp/dpac_ssi. Accessed March 10, 2010.

28. Mangram AJ, Horan TC, Pearson ML, Silver LC and Jarvis WR: Guideline for prevention of surgical site infection. Infect Control Hosp Epidemiol 20: 247-264, 1999.

29. Pulido L, Ghanem E, Joshi A, Purtill JJ and Parvizi J: Periprosthetic joint infection: The incidence, timing, and predisposing factors. Clin Orthop Relat Res 466: 1710-1715, 2008.

30. Choong PF, Dowsey MM, Carr D, Daffy J and Stanley P: Risk factors associated with acute hip prosthetic joint infections and outcome of treatment with a rifampinbased regimen. Acta Orthop 78: 755-765, 2007. 
31. Phillips JE, Crane TP, Noy M, Elliott TS and Grimer RJ: The incidence of deep prosthetic infections in a specialist orthopaedic hospital: A 15-year prospective survey. J Bone Joint Surg Br 88: 943-948, 2006.

32. Assicot M, Gendrel D, Carsin H, Raymond J, Guilbaud J and Bohuon C: High serum procalcitonin concentrations in patients with sepsis and infection. Lancet 341: 515-518, 1993.

33. Laffey JG, Boylan JF and Cheng DC: The systemic inflammatory response to cardiac surgery. Anesthesiology 97: 215-252, 2002.

34. Jebali MA, Hausfater P, Abbes Z, Aouni Z, Riou B and Ferjani M: Assessment of the accuracy of procalcitonin to diagnose postoperative infection after cardiac surgery. Anesthesiology 107: 232-238, 2007

35. Laifer G, Wasner M, Sendi P, Graber P, Gratzl O, Huber P, Fluckiger U and Zimmerli W: Dynamics of serum procalcitonin in patients after major neurosurgery. Clin Microbiol Infect 11: 679-681, 2005

36. Oberhofer D, Rumenjak V, Lazić J and Vucić N: Inflammatory indicators in patients after surgery of the large intestine. Acta Medica Croatica 60: 429-433, 2006 (In Croatian).

37. Lo E, Nicolle LE, Coffin SE, Gould C, Maragakis LL, Meddings J, Pegues DA, Pettis AM, Saint S and Yokoe DS: Strategies to prevent catheter-associated urinary tract infections in acute care hospitals: 2014 update. Infect Control Hosp Epidemiol 35: 464-479, 2014

38. Foxman B: The epidemiology of urinary tract infection. Nature Rev Urol 7: 653-660, 2010.

39. Carsin H, Assicot M, Feger F, Roy O, Pennacino I, Le Bever H, Ainaud $\mathrm{P}$ and Bohuon C: Evolution and significance of circulating procalcitonin levels compared with IL-6, TNF alpha and endotoxin levels early after thermal injury. Burns 23: 218-224, 1997.
40. Wanner GA, Keel M, Steckholzer U, Beier W, Stocker R and Ertel W: Relationship between procalcitonin plasma levels and severity of injury, sepsis, organ failure and mortality in injured patients. Crit Care Med 28: 950-957, 2000.

41. Uçkay I, Garzoni C, Ferry T, Harbarth S, Stern R, Assal M, Hoffmeyer P, Lew D and Bernard L: Postoperative serum pro-calcitonin and C-reactive protein levels in patients with orthopedic infections. Swiss Med Wkly 140: w13124, 2010.

42. Boussekey N, Leroy O, Georges H, Devos P, D'Escrivan T and Guery B: Diagnostic and prognostic values of admission procalcitonin levels in community-acquired pneumonia in an intensive care unit. Infection 33: 257-263, 2005.

43. Hügle T, Schuetz P, Mueller B, Laifer G, Tyndall A, Regenass S and Daikeler T: Serum procalcitonin for discrimination between septic and non-septic arthritis. Clin Exp Rheumato 26: 453-456, 2008.

44. Fottner A, Birkenmaier C, von Schulze PC, Wegener B and Jansson V: Can serum procalcitonin help to differentiate between septic and nonseptic arthritis? Arthroscopy 24: 229-233, 2008.

45. Faesch S, Cojocaru B, Hennequin C, Pannier S, Glorion C, Lacour B and Chéron G: Can procalcitonin measurement help the diagnosis of osteomyelitis and septic arthritis? A prospective trial. Ital J Pediatr 35: 33, 2009.

46. Bottner F, Wegner A, Winkelmann W, Becker K, Erren M and Götze C: Interleukin-6, procalcitonin and TNF-alpha: Markers of peri-prosthetic infection following total joint replacement. J Bone Joint Surg Br 89: 94-99, 2007. 